\title{
Rapid change, no simple solutions
}

In his most recent book (21 Lessons for the 21st Century, Jonathan Cape, 2018), Yuval Noah Harari sets out what he believes to be, as the title suggests, the 21 most critical lessons for this century, in the context of the current state of the world. The 21 lessons are grouped into five sections, with titles such as 'The Technological Challenge', and 'Despair and Hope'. But two issues drawn from two of the sections, have messages of significance for science and education.

In the Introduction (p. ix), Harari points out that:

In a world deluged by irrelevant information, clarity is power. In theory, anybody can join the debate about the future of humanity, but it is so hard to maintain a clear vision. Frequently, we don't even notice that a debate is going on, or what the key questions are.

In what follows, I draw on the lessons titled Ignorance (15); Post-truth (17); Science Fiction (18) and Education (19) - although not in any particular order.

The main thrusts of Harari's arguments are that as a species we find it difficult to escape the 'realities' of previous eras, especially those of the Industrial Revolution and its various mutations and physical structures; and that we have a tendency to replace them with false representations of what a future world (or worlds) might be like - the worlds, as he puts it, that are presented in science fiction movies.

On one hand, we struggle to move into the rapidly changing world that is happening around us, while on the other we are given fictions about the future that is emerging. Clearly these are generalisations, but they are prevalent and persistent enough to influence everything from the pattern of emerging populist politics that foregrounds nationalism, to our ignorance of the kind of world that scientific revolutions are capable of offering.

Two recurring themes in his book are (1) the benefits and other implications of scientific and technological changes of a radical nature, barely imaginable 10 years ago; and (2) archaic and increasingly irrelevant approaches to education and the related blizzard of information (and fake information) now easily accessible to anyone with a smartphone.

Starting with schooling, he points out that, for the greater part, schools are physically and intellectually still modelled on the lessons and practices of the Industrial Revolution era (yet we are already on the brink of the fifth), particularly, the production line. So, many schools still look like marginally benign factories in which children learn along a production line of facts - where millions of 'pieces', right or wrong, already abound. Two of the most important reasons why this form of schooling is not just inappropriate but wrong, lie in the fact that the world is awash with facts, and that change is now happening at a pace of rapidity previously unknown and - because of the rapidity and often unexpected nature of scientific development - largely unpredictable.
What is needed, then, apart from the essential 'three R's' is not more facts or accessible information, but the 'four C's': critical thinking, communication, collaboration and creativity. These four C's are essential in facing the reality that strangeness and the unexpected are already the new normal, as is the fact that rapid change is our only constant. But teaching both the R's and the C's is not easy (least of all in productionline schools) and so must continue, at ever more demanding levels, in higher education. For without them, the three R's become irrelevant in a world in which seeking development, discerning between fact and postfact, and making the most of change, are core needs.

However, it is not just the school system that militates against the needed changes. Politics and politicians play their own role, as is increasingly being seen in more and more countries. The reason why these movements are problematic is that they rely on the growth of, and support for, groupthink, mostly based of fake information, but powerful enough to lead to the situations currently prevalent in England, the USA, Brazil, Turkey, Russia and Hungary, amongst others. Groupthink not only flourishes on the basis of post- or fake-fact, but also militates formidably against questioning, freedom of thought, and the four C's practised by individuals.

And yet science and technology survive and thrive, even as political movements control school learning and undermine freedom of thought and intellectual creativity, ban university courses and arrest or dismiss academics (5800 in Turkey alone), or deny hard scientific realities such as global warming.

The war against mosquitoes and malaria is steadily being won; sophisticated algorithms have changed the world of finance in radical ways; we know more about our human origins, and more accurately, than ever before; and the algorithms that drive artificial intelligence (Al) are changing the ways in which a host of human activities are undertaken - mostly successfully. But even in these positive areas, the absence of the four C's represents other major challenges. Revolutions in biotechnology and information technology made by engineers and others emerge in the context of the designers frequently knowing very little about the ecological and political implications of their successes. Without individual freedom to think and to apply the four C's, what happens to the ability to encounter and assess ethical issues such as the differences between right and wrong, or what is just and what unjust?

On balance, while change is rapid and unpredictable, while science and technology are changing the world and the ways in which we do things and live our lives, two factors are creating major problems: an education system that is, in large part, not keeping pace with the needs of young (and not so young) people; and political expediency which prefers populations whose behaviours are post-truth based and who fear individual, critical and considered thinking.

There are no simple solutions, of course. But if any one need emerges, then it is for enlightened scientists to engage more fully and consistently in debates in the public spheres of politics and education. 